\title{
VISÃO DOS PROFESSORES DA REDE PÚBLICA ESTADUAL DE SUMÉ (PB) SOBRE AS DIFICULDADES NA CONDUÇÃO DE ACCÕES EM EDUCAÇÃO AMBIENTAL
}

\author{
Maria Auxiliadora Alves Evangelista ${ }^{1}$ \\ Adriana de Fátima Meira Vital ${ }^{2}$
}

\begin{abstract}
RESUMO: Os temas ambientais têm, nos últimos tempos, ocupado grande espaço na nossa sociedade: degradação do solo, poluição da água, aquecimento global, falta de saneamento básico, lixo, dentre tantas outras situações, levam a inúmeras reflexões quanto a responsabilidade de cada um na construção do desenvolvimento sustentável, desde que o consumismo desenfreado, gerando atitudes insanas e por demais inconsequentes, evidencia-se na situação de esgotamento dos recursos naturais. A escola é um espaço aberto a essas reflexões e é necessário, senão urgente, que a comunidade escolar desperte para a realidade dos problemas que permeiam o seu habitat e desenvolva campanhas que defendam o Meio Ambiente, trabalhando de forma conscienciosa a abordagem da Educação Ambiental (EA). A presente pesquisa foi conduzida em duas escolas da rede pública estadual de Sumé, município do Cariri Paraibano e objetivou avaliar a percepção dos professores sobre a EA e as dificuldades nomeadas para a condução de ações e projetos em EA. Os resultados apontam que a EA não está inserida nos conteúdos programáticos das disciplinas de forma sistematizada, que os professores não recebem apoio para uma formação continuada na temática ambiental e que não contextualizam os conteúdos de sala para a convivência com o Semiárido. As ações se fazem presentes em datas específicas, não há projetos continuados em EA e os professores reclamam da ausência de políticas públicas que enfatizem o cuidado com a educação básica no contexto da EA, contudo esses atores são bastante receptivos à discussão de assuntos da sua realidade em relação à EA.
\end{abstract}

Palavras-chave: Educação Ambiental; Semiárido; Educação Contextualizada.

\footnotetext{
${ }^{1}$ Especialista em Educação Contextualizada para a Convivência com o Semiárido. E-mail: auxiliadoraevangelista@hotmail.com.

${ }^{2}$ Doutoranda em Ciência do Solo pela UFPB, professora da Unidade Acadêmica de Tecnologia da UFCG; Membro do colegiado do curso superior de Tecnologia em Agroecologia. E-mail: vital.adriana@ufcg.edu.br.
}

Revbea, Rio Grande, V. 8, № 2:150-163, 2013. 


\section{INTRODUÇAO}

A Natureza vem, ao longo da história da humanidade, sofrendo dominação e agressão continuadas (PADUA, 2002). Chegamos a um tempo em que a capacidade de limite de suas forças está em colapso: são situações diversas de degradação que se sucedem, gerando desequilíbrio ambiental e aviltamento da condição humana.

Para tentar minorar essa situação, mitigando os impactos negativos da ação humana sobre o Meio Ambiente é imprescindível que se envidem esforços no sentido de (re)educar o ser humano. E o espaço mais apropriado para tal empreendimento, além da família é a escola.

A escola é, também, o espaço onde é possível se aventurar em outras áreas, rumo a novos conhecimentos, de modo a levar os educando a compreender e vivenciar a importância de um novo paradigma, de renovação de valores e atitudes frente à vida. Nesse sentido, a Educação Ambiental (EA) trabalhada de forma crítica e transformadora busca auxiliar professores e educandos em sua formação integral.

É possível compreender que a tendência da EA na escola é tornar-se não só uma prática educativa, ou uma disciplina a mais no currículo, mas sim consolidar-se como uma filosofia de educação presente em todas as disciplinas existentes, e possibilitar uma concepção mais ampla do papel da escola no contexto ecológico local e planetário (REIGOTA, 1999).

É nessa perspectiva que deve se situar: como interface de questionamentos sobre atitudes, valores e posicionamentos que determinam 0 estabelecimento da vida com qualidade para todos.

O estabelecimento da EA vem sendo trabalhada de forma interdisciplinar, objetivando sensibilizar as pessoas para o despertar de consciência pra um novo padrão de vida, que priorize ações que enfatizem a afetividade e o respeito pelo ambiente natural.

É possível entender que atualmente as atividades organizadas nas escolas de forma geral têm buscado incentivar ações em EA. Embora nem sempre em grande número, esses projetos objetivam a sensibilização ecológica dos envolvidos. Há, entretanto uma carência na necessidade de se desenvolverem atividades ligadas à temática ambiental, como há carência, no contexto geral dos conteúdos escolares, de se abordar temáticas do cotidiano nos programas e projetos de EA e há, igualmente necessidade de se contextualizar à vivência do local para que os educandos sintam-se pertencentes ao seu núcleo e que assim possam interagir melhor nos diversos programas, como protagonista de sua vida.

Se a escola é o espaço propício ao desenvolvimento de uma visão crítica da realidade, oportunizando e estimulando a participação efetiva dos alunos, o papel do educador é de fazer com que este espaço seja realmente um ambiente de interação, de sensibilização, pois que a este profissional cabe a missão, dentre outras de relevante interesse, de permitir o desenvolvimento 
desta postura crítica, reflexiva, diante da realidade local e global, o que fundamenta os valores para a construção da cidadania ativa, resgatando direitos, apontando deveres e promovendo uma nova ética, capaz de conciliar os caminhos do binômio Homem-Natureza.

Por oportuno é preciso enfatizar a necessidade do estabelecimento de políticas públicas que postulem pelo fortalecimento da educação básica, essencial na construção do diálogo para a formação plena do ser humano. Muito embora os avanços alcançados nas últimas décadas, que geraram inovações diversas e contemplaram igualmente as estratégias metodológicas e os materiais didáticos, ainda há uma grande lacuna no universo escolar, sobretudo no que se refere a dimensão ambiental do conhecimento (GUERRA; ABÍLIO, 2006).

Nesse contexto, é indispensável que o professor esteja ciente de seu valor e preparado para trabalhar as questões da temática ambiental com autoridade, sobretudo porque, conforme Fortunato e Neto (2006) a relação entre a formação dos educadores e o conhecimento da realidade emerge como fundamental para que os sujeitos da ação educativa sejam igualmente sujeitos da construção e da transformação da realidade. Assim sendo, objetivou-se neste trabalho analisar a percepção dos professores da rede pública estadual de Sumé - PB, sobre a construção da EA e as dificuldades sentidas para efetivar as ações.

\section{MATERIAL E MÉTODOS}

Para se empreender a presente pesquisa, foram estabelecidos os contatos necessários para apresentação da proposta às escolas. A pesquisa desenvolvida neste trabalho foi do tipo quantitativa, que é apropriada para perceber tanto opiniões, atitudes e preferências, como comportamentos (CASTILLO, 2003). Foram utilizados igualmente elementos da pesquisa qualitativa, que segundo Moreira (2004), pode ser associada á coleta e análise de textos. No presente estudo privilegiou-se a busca de referências bibliográfica de teóricos das áreas de Educação Ambiental e Educação Contextualizada para a Convivência com o Semiárido, além de pesquisas na Internet, isso por que para se desenvolver uma pesquisa de natureza educacional, é necessário possuir domínio do conteúdo teórico e conceitual por meio de leituras específicas.

Segundo Trindade (2003 apud CASTILLO, 2003) a análise de dados quantitativos e dos cruzamentos entre as diversas informações coletadas vão produzir algo qualitativo e vão possibilitar ao pesquisador tirar conclusões que não poderiam ser tiradas sem o levantamento e o cruzamento de informações quantitativas.

A pesquisa foi desenvolvida em duas unidades escolares de Ensino Fundamental II e Médio do Município de Sumé - PB: a Escola Estadual de
Ensino Fundamental e Médio Professor José Gonçalves de Queiroz e a Escola Estadual de Ensino Fundamental e Médio Padre Paulo Roberto de Oliveira.

Revbea, Rio Grande, V. 8, № 2:150-163, 2013. 
O instrumento utilizado foi o questionário com perguntas fechadas. Com os professores a finalidade foi de investigar o conhecimento e o grau de atualização sobre Educação Ambiental. Foram entregues questionários a todo o corpo docente das referidas escolas, contudo, foram devolvidos respondidos apenas vinte e cinco. É importante destacar que o anonimato dos mesmos fora preservado.

Os resultados dos questionários foram tabulados utilizando-se a análise de gráficos a partir do software Excel.

\section{CARACTERIZAÇÃO DO MUNICÍPIO}

A cidade de Sumé, localizada na região do Alto Rio Paraíba, inserida no Polígono das Secas, tem uma área de 864 Km2 e está localizada na microrregião dos Cariris Velhos, Centro do Estado da Paraíba numa altitude media de 533m. Tem como municípios limítrofes ao norte São José dos Cordeiros (PB) e Itapetim (PE); ao sul, Camalaú e Monteiro; a leste, Serra Branca e Congo e a oeste, Ouro Velho, Prata e Monteiro, todos no estado da Paraíba. O clima é do tipo Semiárido quente, com chuvas de verão, caracterizado por precipitações e temperaturas elevadas que ocasionam acentuada evaporação, principalmente no período de junho a janeiro.

A vegetação é constituída pela Caatinga xerofítica, com vegetação dotada, em sua maioria, de reservatórios de água que permitem sua sobrevivência nos períodos de seca mais prolongados e rigorosos, comum do sertão nordestino, sendo representada por bromeliáceas e cactáceas. As principais espécies são as popularmente conhecidas: macambira, marmeleiro, xiquexique, facheiro, jurema preta, etc. As árvores de médio porte são encontradas ao longo dos riachos e rios, devido a maior umidade destes locais, a exemplo da umburana, catingueira, umbuzeiro, baraúna.

Os solos são em geral, jovens, por isso apresentam ainda bastante pedregosidade e pouca profundidade, necessitando de conhecimentos que direcionem práticas de uso e manejo sustentáveis. Segundo o Sistema Brasileiro de Classificação dos Solos (EMBRAPA, 2006) são classificados nas seguintes ordens do primeiro nível categórico: planossolos, argissolos, neossolos, luvissolos e cambissolos.

A região detém reservas vegetais que estão sendo consumidas paulatinamente, pelos fornos e caldeiras e para a fabricação de carvão por processos rudimentares, contudo existem ainda áreas preservadas, Uma das árvores nativas que têm apresentado uma devastação agressiva, em decorrência das atividades antrópicas para a confecção do doce conhecido popularmente como 'cafofa do umbu' é a Spondias tuberosa, nosso umbuzeiro.

Apesar das adversidades pelas quais passa essa região, o Cariri possui belezas naturais diversas em forma de vales, serras, plantas e animais, que devem ser preservadas. As cidades do Cariri possuem um belo patrimônio arquitetônico e histórico que vale a pena conferir. O povo é forte e hospitaleiro. 
Conhecer essas potencialidades é ponto crucial para o desenvolvimento local e para a valorização dos recursos naturais.

\section{O UNIVERSO PESQUISADO}

1) A Escola Estadual de Ensino Fundamental e Médio Professor José Gonçalves de Queiroz foi criada em 09 de março de 1974, no governo Ivan Bichara Sobreira, através do Decreto № 3.887 para funcionamento inicial do $1^{\circ}$ Grau (atual Ensino Fundamental - Fase II). Depois, em 11 de abril de 1977, pelo Decreto № 7.235, foi implantado o 2ํㅡㅁau (atual Ensino Médio). A escola está localizada à rua Professora Guiomar Coelho S/N, bairro do Pedregal, Sumé-PB (Fone 3353-2695) e ocupa uma área de 12.000m2, espaço físico privilegiado no Cariri, sendo considerada uma das maiores da região.

A estrutura física está assim organizada: uma área térrea, outra área de $1^{\circ}$ andar e um amplo terreno anexo (campo de futebol e vôlei de areia, desativados). A disposição possibilita ao educando identificar sua sala de aula e localizar-se nas dependências da escola com facilidade.

No $1^{\circ}$ andar existem 12 salas de aula, 01 sala de vídeo e 02 baterias de banheiro (feminino e masculino). No térreo, estão distribuídas 14 salas de aulas As demais dependências são: 01 sala de direção com almoxarifado, 01 sala de secretaria com arquivo, 01 auditório, 01 laboratório de informática com 10 computadores, com internet, 01 laboratório de ciências com alguns equipamentos, 01 sala de coordenação com 01 sala anexa, 01 sala de professores, 01 cozinha com despensa e refeitório, 01 banheiro para funcionários, 02 baterias de banheiro (feminino e masculino), 01 sala do Pro Jovem Urbano, 01 sala de vídeo, 01 biblioteca, 01 sala de leitura, 01 quadra poliesportiva coberta com 02 banheiros e vestiários anexos.

A escola dispõe de alguns equipamentos, tais como: computadores; retroprojetor; data show; tela de projeção; caixas de som com mesa e microfones; máquinas fotográficas digitais; micro e mini systens; DVDs; TV de plasma e outras; máquina de Xerox; impressoras sem e com scanner; aparelho de fax; notebook. Na sala de leitura existem os livros didáticos, paradidáticos, literatura infanto-juvenil, enciclopédias, jornal, revistas, jogos pedagógicos e dicionários.

A escola atende um público oriundo da zona urbana e rural do município, nas modalidades de Ensino Fundamental - Fase II, Ensino Médio e PEJA - Programa de Educação de Jovens e adultos (Fundamental e Médio), nos três (03) turnos - manhã, tarde e noite. Neste ano letivo de 2011 possui 1.259 educandos, sendo 656 do Ensino Fundamental, 379 do Ensino Médio e 224 da EJA.

Funcionam 36 turmas de ensino regular (18 matutinos, 18 vespertino ensino fundamental e médio); 09 turmas da PEJA (noturno - ensino fundamental e médio) e ainda, 10 turmas do Programa Pro Jovem Urbano (noturno), fazendo um total de 55 turmas, na faixa etária de 09 a 51 anos,

Revbea, Rio Grande, V. 8, N²:150-163, 2013. 
mostrando grande heterogeneidade, no que se refere à idade, classe social, nível cultural, etc.

No ano da pesquisa (2011) sessenta e cinco professores compunham o corpo docente da escola, distribuídos em três categorias dentro da escola: os efetivos - aqueles que fizeram concurso (37), os pro-têmpores - aqueles que são contratados que são contratados de longos tempos (11), e os contratados - a cada ano de acordo com a necessidade da escola, (17).

É importante destacar que 29 educadores possuem pós-graduação (especialização), 17 têm licenciatura em diversas áreas e 18 cursam o ensino superior.

2) A Escola Estadual de Ensino Fundamental e Médio Padre Paulo Roberto de Oliveira está situada no bairro Frei Damião de Bozzano tendo como ponto de referência a sua esquerda a fazenda Simeão, à sua direita, a Escola Agrotécnica de Sumé.

Construída em 26 de novembro de 1998, teve sua natureza jurídica e situação legal de estabelecimento promulgada pela a Lei 6.997 de 18 de julho de 2001 no governo de José Targino Maranhão. O nome da escola foi uma homenagem ao padre da Paróquia local.

A estrutura física da escola está assim disposta: 08 salas de aula, 13 banheiros, inclusive um para deficientes, 01 diretoria, 01 secretaria, 01 cozinha com refeitório, 01 sala de professores, 01 sala para coordenação, 01 biblioteca, 02almoxarifado, 01 quadra de eventos, 01 campo de terra para esportes e eventos.

O corpo docente atualmente é formado por 28 professores sendo 25 com licenciatura e 03 ainda cursando o ensino superior.

A escola funciona atende 447 alunos divididos em 03 turnos, contando com o ensino fundamental e médio. O planejamento da escola é feito mensalmente, envolvendo toda a equipe técnica, as propostas são flexíveis, considerando a realidade de cada sala de aula. A avaliação visa contribuir com a função básica da escola, promover acesso ao conhecimento, ela é feita de forma contínua e diagnostica. Todos que fazem parte da escola estão engajados em constante batalha pela melhoria do ensino-aprendizagem. A filosofia da escola é criar condições necessárias para que o educando encontre e crie oportunidades de exercer sua cidadania em sua plenitude, fornecendo meios para progredir no campo profissional e em estudos posteriores.

\section{RESULTADOS E DISCUSSÃO}

Os questionários aplicados ao corpo docente das duas escolas da rede pública estadual de Sumé apontam para uma falta de preparação e desmotivação daqueles profissionais com relação à temática Educação Ambiental, assim como para a falta de interesse da própria escola e dos órgãos públicos em investir na formação desses profissionais. 
A análise dos questionários permite uma reflexão sobre a caminhada solitária de alguns desses profissionais, cuja voz muitas vezes não encontra eco na sua busca; permite também observar que ainda é grande a lacuna entre a teoria para se fazer Educação Ambiental e a prática das escolas, sobretudo porque muitos professores confessam sua insegurança em abordar determinadas temáticas.

Num primeiro momento buscou-se compreender a percepção destes sobre Educação Ambiental. Preservar e Conservar a Natureza foi 0 entendimento geral. Esse pensamento conservacionista/protecionista também foi percebido por Carneiro (2007) quando trabalhou com docentes de escolas públicas de Curitiba (PR) (49,5\% dos entrevistados assim se posicionaram). Abilio e Goms (2010), trabalhando com professores de uma escola pública de São João do Cariri (PB) constataram que essa visão protecionista surge em menor grau de representatividade $(9,09 \%)$.

Com relação aos problemas que podem ser relacionados às questões ambientais, há uma compreensão geral da temática, pois todos os assuntos elencados no questionário foram mencionados pelos professores, com mais expressividade para a poluição das águas, degradação do solo e extinção de espécies (Figura 1).

Assinale dentre os problemas abaixo, o que você acha que tem relação com as questões ambientais.

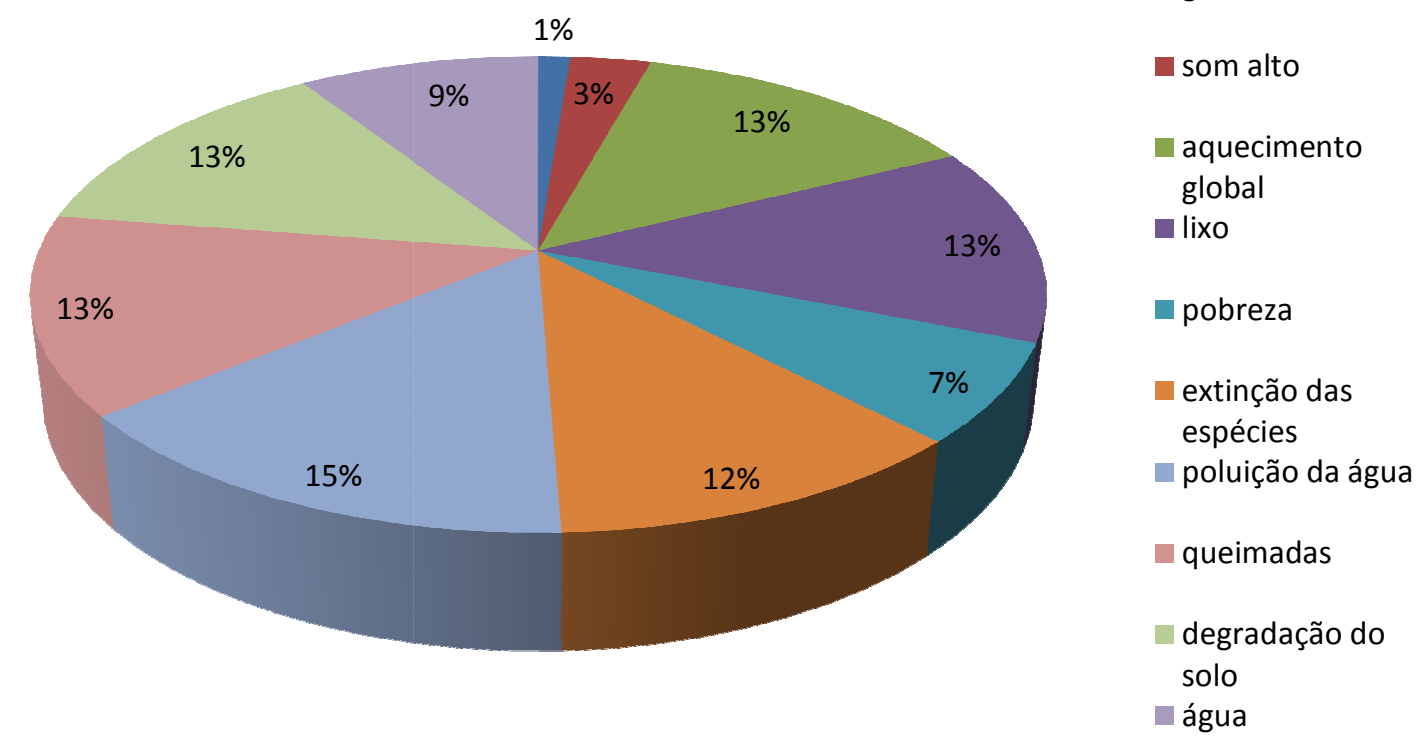

Figura 1: Percepção dos professores sobre os problemas ambientais.

Revbea, Rio Grande, V. 8, № 2:150-163, 2013. 
Embora compreendendo a relevância de trabalhar a EA nos conteúdos das diversas disciplinas $14 \%$ dos professores afirmam que a mesma não está inserida no conteúdo das disciplinas. Para aqueles que dizem trabalhar a temática na sala de aula apenas $14 \%$ dizem abordar a temática da convivência com o Semiárido, o que nos faz inferir que os diversos desafios apresentados no ambiente local passa quase despercebido (Figura 2).

A maioria considera que recursos como água e solo sejam inesgotáveis em suas funções e uma quantidade expressiva de professores demonstra familiaridade com o tema que é preocupação crescente das populações, sobretudo daquelas que vivem situações de déficit hídrico acentuado e de degradação das terras, a exemplo dos habitantes do semiárido brasileiro. Contudo, uma pergunta que surge é: sendo os temas água (poluição, escassez, assoreamento dos mananciais, transposição dos rios, etc.) e o solo (degradação, desertificação, salinização, erosão, etc.) tão importantes para a região, por que esta temática não se faz presente nos conteúdos escolares de forma continuada e contextualizada?

\title{
Na sua opinião, como a EA está inserida no currículo da escola?
}

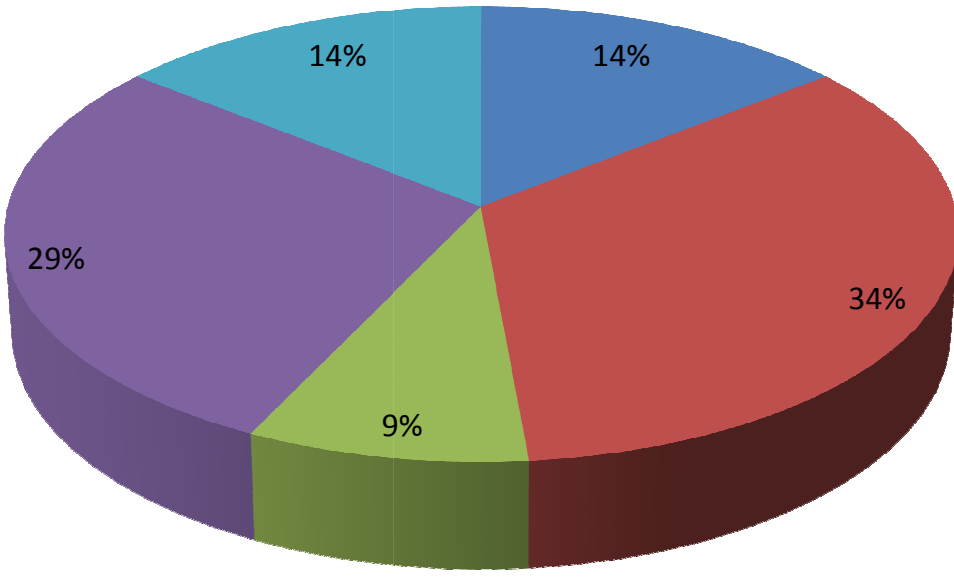

\author{
não está \\ com poucas \\ atividades \\ com atividades que \\ priorizam os \\ problemas locais \\ com atividades que \\ priorizam os \\ problemas globais
}

Figura 2: Inserção da EA no currículo escolar.

Em conversas informais quando da aplicação do questionário, foi possível observar que, com relação ao entendimento destes sobre a biodiversidade há uma compreensão de que é a grande responsável no processo do equilíbrio ambiental. Para a maioria dos professores a melhor 
definição de Meio Ambiente ainda é tudo o que se relaciona a paisagem natural e o lugar onde o homem e a natureza estão em constante interação.

Entretanto, perguntados sobre como se posicionam em relação aos cuidados com a Natureza, 67\% considera que tudo deve ser preservado na íntegra, pois o homem é um predador e invasor, o que denota uma visão bastante fragmentada da Educação Ambiental e da Natureza, desde que o ser humano é parte desse todo complexo, e o de que se necessita para uma vida em plenitude, é o entendimento das inter-relações, das conexões ocultas, das interdependências (Figura 3).

Segundo Malvezzi (2007) para compreender o bioma Caatinga é preciso compreender suas gentes. O ser humano faz parte dos biomas e para manter padrões de convivência adequados é fundamental estudar a natureza das coisas e o ser humano, compreendê-los, desenvolvendo assim os postulados da educação contextualizada.

Na sua relação com a Natureza você:

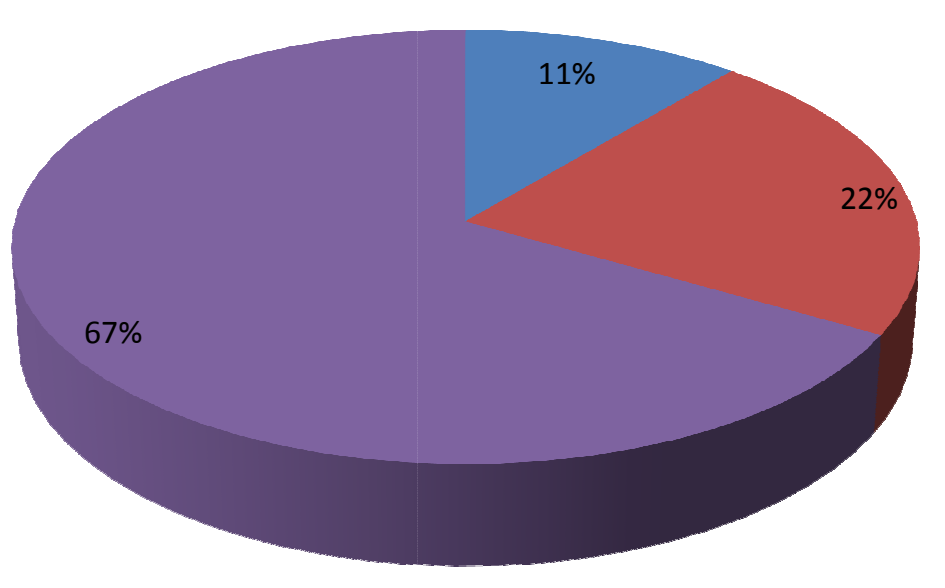

\author{
- Percebe que não vê \\ ou por do sol a \\ muito tempo \\ Aceita que poucas \\ prefeituras \\ consigam manter \\ uma área verde \\ Acha que tudo deve \\ ser preservado na \\ íntegra,pois o \\ homem é um \\ predador invasor
}

Figura 3: Relação dos professores com a Natureza.

Os professores mencionam que os meios ou instrumentos de informação sobre EA que mais utilizam para organizar seus estudos são, sobretudo televisão, revistas, internet e livros.

Nessa perspectiva é interessante observar que material didático está 
esse material, bem como os educadores, buscam novas fontes de informações para inserir nas atividades as diversas situações ambientais do local, pois evidencia-se por suas falas uma carência bastante acentuada de um material didático cuja proposta seja mais aproximada do universo dos educandos, fazendo-se urgente uma reformulação dos conteúdos abordados, de forma a trazer para a sala de aula o cotidiano do ambiente desses educandos, o que resultará, por certo, em mais entusiasmo pelo sentimento de pertencimento que é próprio do ser.

Há ainda a carência de uma formação continuada em EA, de fóruns de discussão, de seminários e palestras durante as etapas de planejamento das atividades do bimestre letivo, quando podem ser discutidas as diversas ações, programas e projetos em Educação Ambiental. Há, sobretudo, a necessidade de uma nova leitura sobre o Semiárido, que busque direcionar o olhar para o bioma Caatinga, evidenciando sua diversidade, sua cultura, sua riqueza, suas potencialidades, bem como suas fragilidades e necessidades (Figura 4).

\section{Que meios ou instrumentos de informação sobre a EA utiliza?}

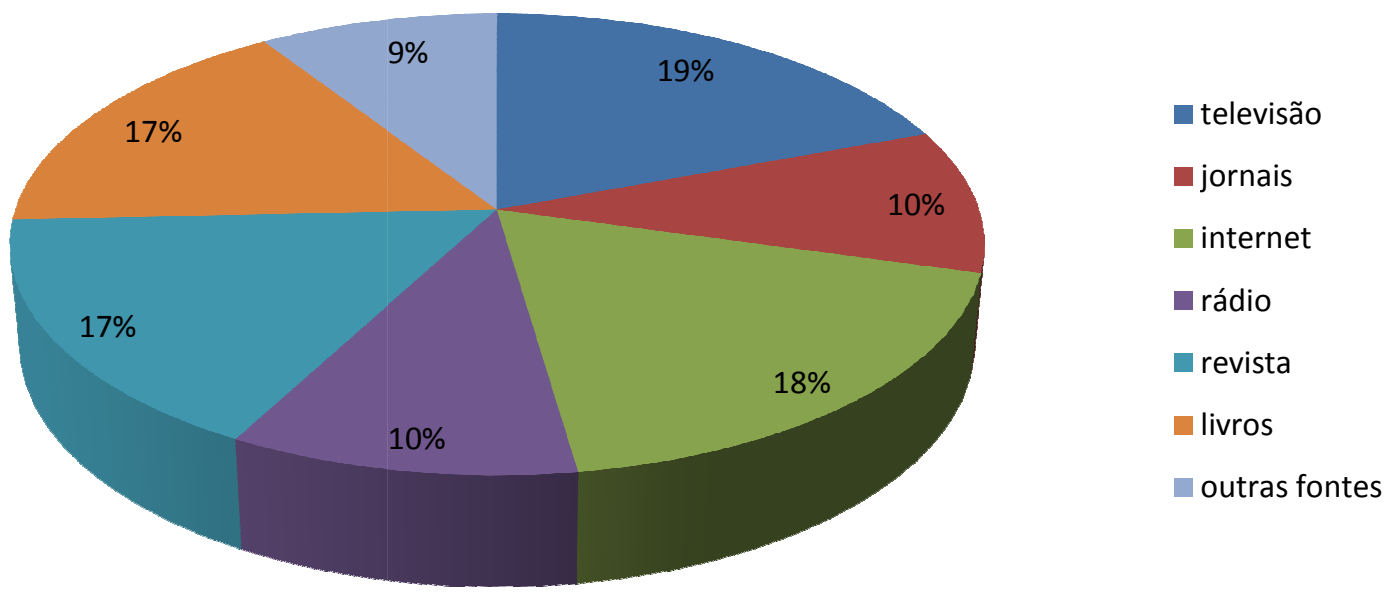

Figura 4: Meios/instrumentos de informação sobre EA.

Quando se arguiu sobre a preocupação da escola na formação continuada dos professores em EA, os entrevistados disseram que as mesmas não têm feito esforço em promover uma melhoria nas condições do ensino, nem facilitado a formação ou especialização do corpo docente em EA (78\%), o que evidencia o descaso do setor na formação do professor e do aluno. 
A formação continuada é fundamental no desempenho das atividades em EA, sobretudo quando se pretende contextualizar o ensino na prática que prioriza uma nova leitura da região. Para Souza e Reis (2003), para obter êxito nesse "novo ser" é necessária a interação entre o conhecer/refletir/intervir, no intuito de redirecionar a ação em sala de aula, pois ao "conhecer a realidade", a escola ampliará as possibilidades de conhecimento promovendo cultura e fazendo emergir os potenciais de cada lugar.

A ausência de atividades que proporcionem uma formação continuada ou uma reciclagem dos conhecimento, uma atualização sobre temas ambientais é bastante relevante para aquisição de uma nova visão de mundo, permitindo aos professores potencializar suas habilidades, renovar suas atitudes e redirecionar, (re)significando seus próprios conceitos, saindo assim de uma postura fragmentada e simplista.

\section{A escola atua na formação continuada do professor em EA? Como?}

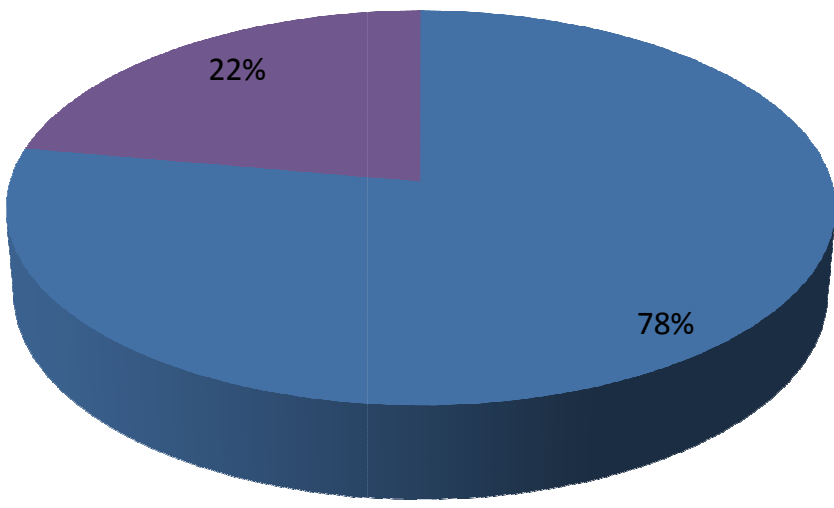

- Não atua na

formação

continuada em EA

- Liberação de carga

horária para EA

Figura 5. Atuação das escolas na formação continuada em EA dos professores.

Perguntados sobre as dificuldades no desenvolvimento de projetos de $E A$, a equipe mencionou a falta de integração entre a equipe e o corpo docente, aliada a falta de recursos humanos qualificados que tragam suporte ao entendimento das questões ambientais. Esses dados apontam para a necessidade de revisão dos projetos pedagógicos das escolas de educação básica que devem funcionar como espaço de integração, compartilhamento de ideias e reflexão sobre as questões ambientais, visando a sensibilização do corpo docente para a implementação de projetos e ações estratégicas em EA. Isso implica em que é indispensável trabalhar a percepção do professor para o entendimento de que a atividade docente vai além do domínio de conteúdos específicos, sendo crucial incorporar em sua práxis valores ético-morais e

Revbea, Rio Grande, V. 8, N²:150-163, 2013. 
humanistas; é essencial trabalhar valores como a afetividade e a compaixão, a solidariedade e o sentimento de pertencimento ao planeta.

As dificuldades mencionadas na condução de atividades em EA nas escolas estudadas não são diferentes de outros estabelecimentos de ensino e dizem respeito a convivência, ao comprometimento, a responsabilidade e ao envolvimento de cada ator social (Figura 6).

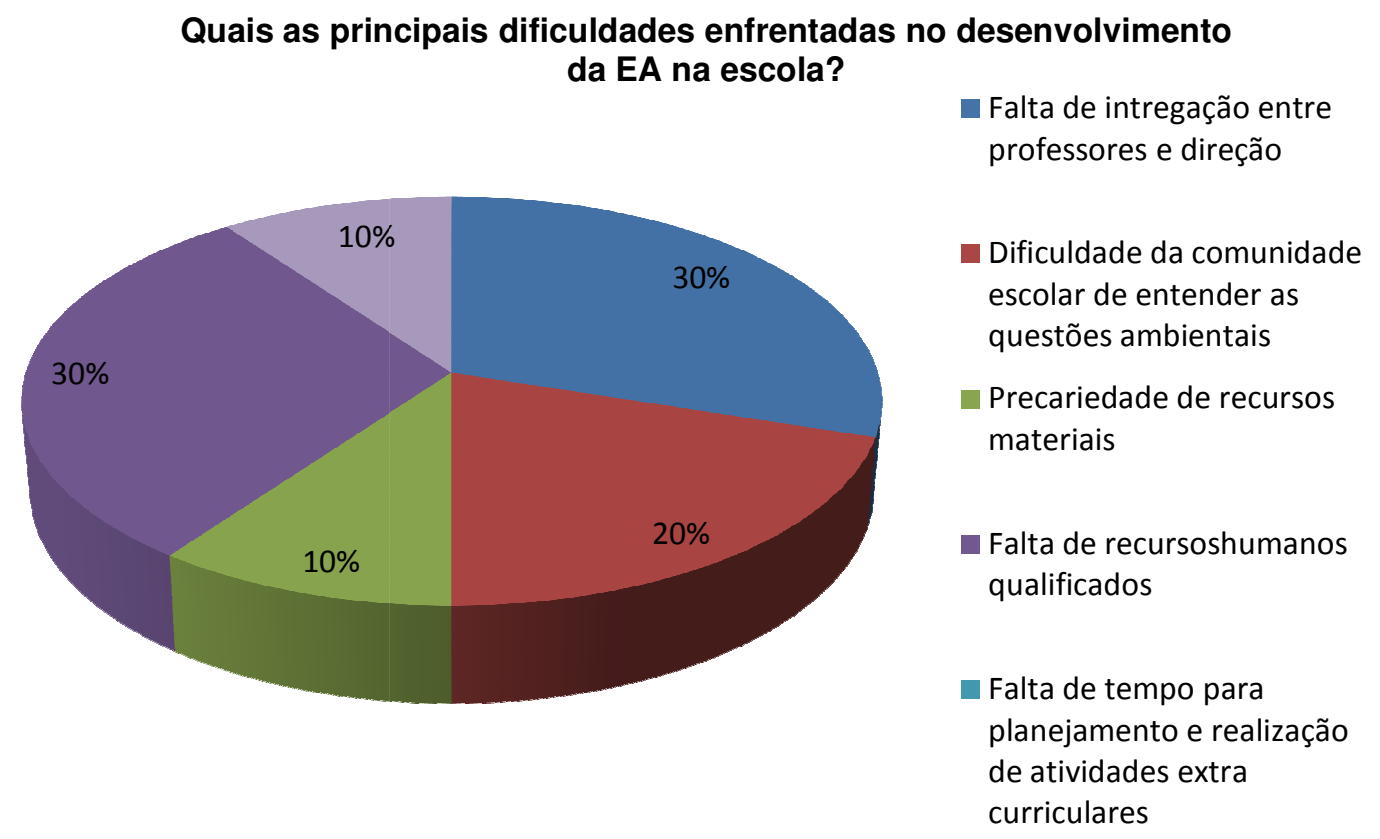

Figura 6: Dificuldades enfrentadas no desenvolvimento de atividades em EA.

\section{CONCLUSÃO}

Os resultados da presente pesquisa indicam que a EA não está inserida nos conteúdos programáticos das diversas disciplinas das escolas estudadas; há, todavia, muito interesse por parte dos educadores em desenvolver atividades em EA, sobretudo na perspectiva do Semiárido. Por outro lado, a pesquisa evidenciou que não há entrosamento entre a equipe pedagógica e o corpo docente no desenvolvimento das atividades em EA. Para os professores, inexiste é a preocupação por parte das escolas em facilitar o acesso a informação e formação continuadas em EA.

Outrossim, foi possível perceber certo constrangimento no tocante ao preenchimento dos questionários, o que evidencia certa preocupação em não apontar falhas no processo escolar, embora alguns dos entrevistados tenham procurado ser bastante criteriosos e verdadeiros em suas buscas pela melhoria do ensino. 
Consideramos que os conhecimentos, dos saberes e fazeres do local, produzidos no cotidiano, fortalecem a relação entre a prática escolar e o contexto sociocultural. Dessa forma, as especificidades do lugar e os elos que os educandos trazem de sua vivência deve ser considerados quando da elaboração das atividades em EA, pois fortalecem os laços e devem funcionar como elementos mediadores do saber do professor e do aluno.

A educação contextualizada é uma educação que precisa fazer sentido na realidade vivida pelas pessoas, no lugar onde elas vivem, pois, se a educação não está a favor de um modelo de desenvolvimento sustentável e integrado ela desconsidera todas as particularidades locais E precisa se tornar uma ferramenta de libertação, como já pretendia Paulo Freire, favorecendo que as pessoas se emancipem que, a partir do local, elas saibam atuar melhor sobre o meio em que vivem e possam assim viver mais felizes (ARANHA, 1997; GVAA, 2009).

Diante desses resultados, torna-se evidente a importância de realizar treinamentos com o corpo docente e a equipe escolar, buscando sobretudo, contextualizar as atividades de EA na temática de convivência com 0 Semiárido. Embora pouco evidenciado, ainda predomina entre os professores entrevistados posturas críticas quanto a pouca expressividade das ações em EA, refletindo práticas inadequadas, apesar de perceberem importância da EA, a sua implementação torna-se difícil em virtude de várias carências já apresentadas.

Salienta-se que para aprimorar e ampliar o conceito como processo educativo é necessário investir na formação dos professores, de maneira a se motivar a construção e reconstrução dos conhecimentos referente ao meio ambiente e a própria EA, que deve ser entendida como importante subsidio do currículo escolar no encontro e na busca de um conhecimento sistemático que complemente os conteúdos, uma vez que, segundo Sato (2002) sustenta todas as atividades humanas e impulsiona os diferentes aspectos da vida humana.

A EA precisa urgentemente ser melhor compreendida no espaço escolar e os professores precisam se apropriar de sua significação e relevância, devendo as instituições governamentais e secretarias diversas proporcionarem espaço adequado para essas reflexões e construções, promovendo ações que priorizem a formação do professor de forma a que seja disseminada as concepções sobre o Meio Ambiente, pretendendo a construção de um novo tempo, de um mundo melhor, mais justo, mais harmônico e sustentável para todos.

\section{REFERÊNCIAS}

ABILIO, F.J.P.; GOMES, C.S. Oficinas ecológicas na formação continuada de professores: um projeto interdisciplinar de Educação Ambiental no Cariri paraibano. In.: ABILIO, F.J.P. (Org.). Educação Ambiental e o ensino de ciências. João Pessoa: Editora Universitária da UFPB. 2010.

Revbea, Rio Grande, V. 8, № 2:150-163, 2013. 
ARANHA, M.L.A. Filosofia da Educação. São Paulo: Moderna, 1997.

CARNEIRO, S.M.M. A Educação Ambiental e a formação de educadores: pesquisas em escolas do ensino fundamental. In:.: GUERRA, A.F.S.; TAGLIEBER, J.E. (Org.). Educação Ambiental: fundamentos, práticas e desafios. Itajaí: Univali. 2007.

CASTILLO, R.A.F.D. Aprendendo sobre pesquisa: pesquisa Qualitativa. 2003 b. Disponível em:

$<$ http://www.ead.unicamp.br/trabalho pesquisa/Pesq quali.htm>. Acesso em: 15 nov. 2010.

CAVALCANTE, M.B; NASCIMENTO, S.M.S.G. Áreas Protegidas na Caatinga: um estudo de caso no Parque Estadual da Pedra da Boca. Artigo apresentado a Disciplina Estudos de Impactos Ambientais (EIA), Curso de Especialização em Ciências Ambientais - FIP/PB, 2006, (mimeo).

DELGADO, B.C.C. Identidade e Sustentabilidade: Critérios de Planejamento Ambiental para o Distrito de Cachoeira, Maranguape - Ce. Fortaleza: [s.n], 2004.

EMBRAPA. Centro Nacional de Pesquisa de Solos. Sistema Brasileiro de Classificação de Solos. Rio de Janeiro, 2006. 512p.

FORTUNATO, M.L.; MOREIRA NETO, M. Educação e Subjetividades: possibilidades formativas para o Semiárido. Caderno Multidisciplinar Educação e Contexto do Semiárido Brasileiro, p. 31-48, 2006.

GUERRA, R.A.T.; ABILIO, F.J.P. Educação Ambiental na escola pública. João Pessoa: FOXGRAF. 2006.

GVAA, Grupo Verde de Agricultura Alternativa. Tecnologias de convivência com o Semiárido, Alternativas viáveis para a Agricultura Familiar no oeste do Rio Grande do Norte. INFOTECNARIDO (Mossoró-RN- Brasil) v.3, n.1, p.12-24 janeiro-dezembro de 2009. Disponível em <www.gvaa.com.br/revista/index.php/INTESA/article/download/453/474> .Acesso em 04/09/2011.

MALVEZZI, R. Semiárido: Uma Visão Holística. Brasília: Confea, 2007. 140p.

MOREIRA, A.F.B. Indagações sobre currículo: currículo, conhecimento e cultura. Brasília: Ministério da Educação, Secretaria de Educação Básica, 2004.48 p.

PÁDUA, J.A. Um Sopro de Destruição: Pensamento Político e Crítica Ambiental no Brasil Escravista, Rio de Janeiro, Jorge Zahar Editor. 2002.

REIGOTA, M. A Floresta e a Escola: por uma educação ambiental pósmoderna. São Paulo: Cortez, 1999.

SATO, M. Educação Ambiental. São Carlos: RIMA. 2002.

SOUZA, I.P.F.; REIS, E.S. Educação para a convivência com o Semiárido: reencantando a educação com base nas experiências de Canudos, Uauá e Curaca. São Paulo: Pirenópolis. 2003. 